$\Delta$ Palabras clave/ Patrimonio, ferrocarril refuncionalización, espacio público.

$\Delta$ Keywords/ Heritage, railroad, refunctionalization, public space.

$\Delta$ Recepción/ 29 diciembre 2016

$\Delta$ Aceptación/ 3 abril 2017

\title{
Recuperación y refuncionalización del patrimonio ferroviario junto al desarrollo de espacio público. Caso Gran Rosario, Argentina
}

\section{Recovery and Refunctionalization of Railroad Assets along the Development of Public Spaces. The Case of Gran Rosario, Argentina}

\author{
Cecilia Inés Galimberti \\ Doctora en Arquitectura, Facultad de \\ Arquitectura, Planeamiento y Diseño, \\ Universidad Nacional de Rosario, Argentina. \\ Profesora de la Facultad de Arquitectura, \\ Planeamiento y Diseño de la Universidad \\ Nacional de Rosario, Argentina. \\ cecilia.galimberti@conicet.gov.ar
}

RESUMEN/ El ferrocarril en Argentina -como en gran parte del mundo- resulta ser un factor esencial de transformación territorial. No obstante, las nuevas tecnologías, los cambios productivoeconómicos y las vicisitudes políticas ocasionan que, con el transcurrir de las décadas, el sistema ferroviario se degrade y se torne obsoleto. Sin embargo, especialmente desde las últimas décadas del siglo XX, se llevan a cabo diversas estrategias de refuncionalización de estos componentes junto al desarrollo de nuevos espacios públicos. A fin de reflexionar sobre estas intervenciones de regeneración urbana, analizamos cuatro casos de estudio correspondientes a la ciudad de Rosario y su área metropolitana, en Argentina. Su análisis crítico nos permite contribuir al conocimiento del rol del patrimonio ferroviario como recurso activo de transformación urbano-territorial, a través de nuevas apropiaciones colectivas de la sociedad. ABSTRACT/ Like in most parts of the world, in Argentina railroad is a key factor in the transformation of territories. However, new technologies, productive-economic changes and political difficulties result in the deterioration of railroad systems rendering them obsolete. Notwithstanding, particularly since the last decades of the 20th century, several refunctionalization strategies have been put in place, along with the development of new public spaces. In order to reflect on these urban recovery interventions, we analyzed four case studies in the city of Rosario and its metropolitan area, in Argentina. The critical analysis makes a contribution to the knowledge on the role of railroad heritage as an active resource of urban-territorial transformation through new collective appropriations by society.

\section{INTRODUCCIÓN.}

resulta ser un motor esencial de desarrollo regional. Especialmente en América Latina, como explica Beltrán-Beltrán (2011), en la segunda mitad del siglo XIX se pasa de una organización espacial basada en una red de caminos reales a un sistema de ferrocarriles que reestructura el territorio. A través de éste se extienden las redes comerciales, se originan urbanizaciones y se establecen nuevos desarrollos productivos, transformando así la configuración regional. Sin embargo, con el transcurrir de los años, el sistema ferroviario se sumerge en una profunda crisis que conduce al deterioro, obsolescencia y desmantelamiento de sus componentes, a pesar del rol primario de estas infraestructuras.

No obstante, en las últimas décadas del siglo XX existe una nueva perspectiva acerca de la herencia del pasado. Siguiendo a Sabaté (2010), en dicho período aparece una concepción amplia del patrimonio como legado de la experiencia y del esfuerzo de una comunidad, como marcas esenciales de la historia propia de cada sociedad. En este sentido, en diversas partes del mundo se llevan a cabo proyectos de recuperación del patrimonio territorial junto al desarrollo de espacio público'. Los espacios y equipamientos que históricamente correspondieron a infraestructuras de comunicación -áreas portuarias y/o ferroviarias-, industrias desactivadas, mercados, entre otros, y que han quedado obsoletos, presentan un enorme potencial para su regeneración como nuevos espacios públicos urbanoterritoriales, posibilitando no solo nuevos ámbitos de encuentro y sociabilización, sino también posicionándose como elementos ordenadores y de articulación interna de los poblados y de éstos con el resto de la ciudad metropolitana (Borja y Muxi 2003). 
A fin de profundizar en el análisis críticointerpretativo sobre esta temática, estudiamos diversos proyectos de creación y/o fortalecimiento del espacio público como consecuencia o derivación de acciones de recuperación del patrimonio ferroviario en el Gran Rosario, Argentina (imagen 1). A través de una metodología cualitativa, utilizamos como principales estrategias de análisis los recorridos exploratorios por el territorio, la observación, el análisis fotográfico, el relevamiento de fuentes documentales y su análisis de contenido -como archivos cartográficos, normativas y documentos de planeamiento- entre otros. Nos focalizamos en cuatro casos representativos de reconversión de grandes predios en nuevos espacios públicos junto a la refuncionalización de componentes ferroviarios. Se destaca el impacto urbano resultante, dado que se trata de importantes componentes subutilizados que, en algunos casos, se encontraban cerrados a la comunidad y que, a través de su transformación, han conducido a diversas

\section{apropiaciones colectivas.}

\section{EL FERROCARRIL COMO MOTOR DE TRANSFORMACIÓN TERRITORIAL.}

El Gran Rosario, localizado en la región pampeana de Argentina, a orillas del río Paraná, se transforma vertiginosamente a partir de la segunda mitad del siglo XIX. Además del rol portuario estratégico a nivel nacional que adquiere Rosario, en dicho período se conforma la red ferroviaria que resulta uno de los factores centrales de transformación regional, dado que se articula un pequeño poblado en torno a cada estación. Es así como surgen la mayoría de las localidades pertenecientes a la Región Metropolitana de Rosario. Los centros poblacionales que emergen en torno a las estaciones del ferrocarril constituyen el área productora adyacente a lo que iba conformándose como la ciudad -puerto de Rosario- junto a políticas de colonización agrícola.

En el año 1910, la organización de la estructura territorial del área de estudio ya se encuentra concluida. Sin embargo, en las primeras décadas del siglo XX, el sistema de movilidad cambia frente al novedoso

- mercado automotor, comenzando la

己. decadencia del sistema ferroviario.
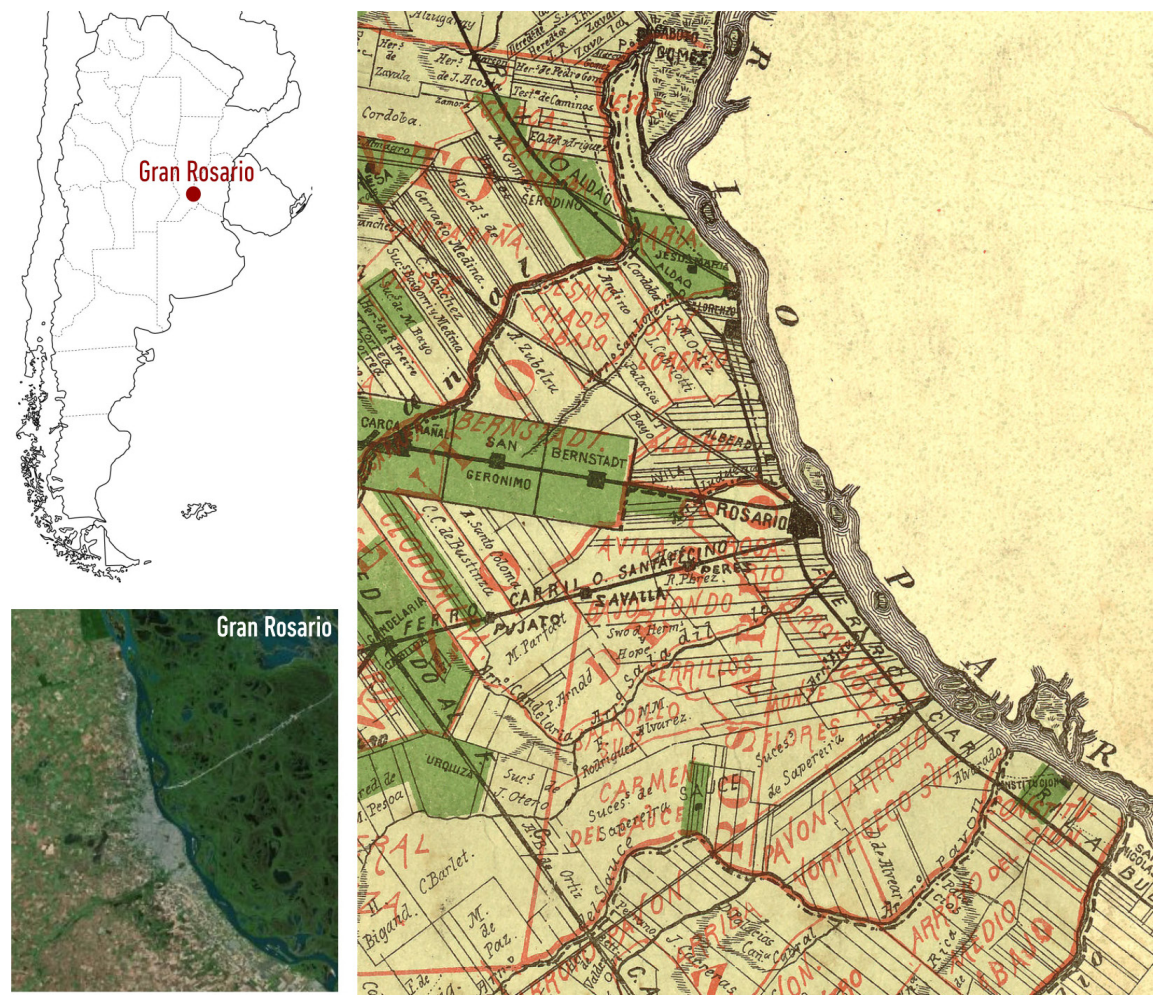

Imagen 1. Localización del área de estudio y sistema ferroviario de la región metropolitana de Rosario en 1889 (fuente: Elaboración propia en base a imagen de Google Earth y fragmento de cartografía del Departamento Topográfico de Santa Fe de 1889, Archivo General de la Nación
A mediados del mismo siglo, el sistema se encuentra frente a una importante crisis, presentando un notable deterioro (Galimberti 2015)

A pesar de diversas propuestas de reestructuración y sistematización ferroviaria -en especial luego de la estatización de los ferrocarriles en 1948y de algunas intervenciones -por ejemplo, el primer caso estudiado en este artículoen el Gran Rosario se produce el proceso de refuncionalización y rehabilitación del patrimonio ferroviario, especialmente desde las últimas décadas del siglo XX luego de la recuperación democrática definitiva en Argentina, en 1983. En el apartado siguiente nos focalizamos en el estudio particularizado de cuatro intervenciones significativas en el ámbito territorial abordado.

\section{RECUPERAR LAS MARCAS DEL PATRIMONIO FERROVIARIO JUNTO A LA CREACIÓN DE ESPACIO PÚBLICO.}

El patrimonio ferroviario regional presenta una riqueza significativa. Rosario resulta punta de lanza en la recuperación de este patrimonio en la región, no solo a través de la refuncionalización de sus estaciones ferroviarias, sino también de múltiples componentes como, por ejemplo: talleres, depósitos, tanques de agua, puentes, conjunto de viviendas, entre otros

Cabe remarcar que la rehabilitación del patrimonio no sucede de manera aislada, sino mayormente en torno a la recuperación de gran parte de las tierras originalmente ferro-portuarias para la creación de espacio público. A continuación, analizamos cuatro casos representativos de este tema. 

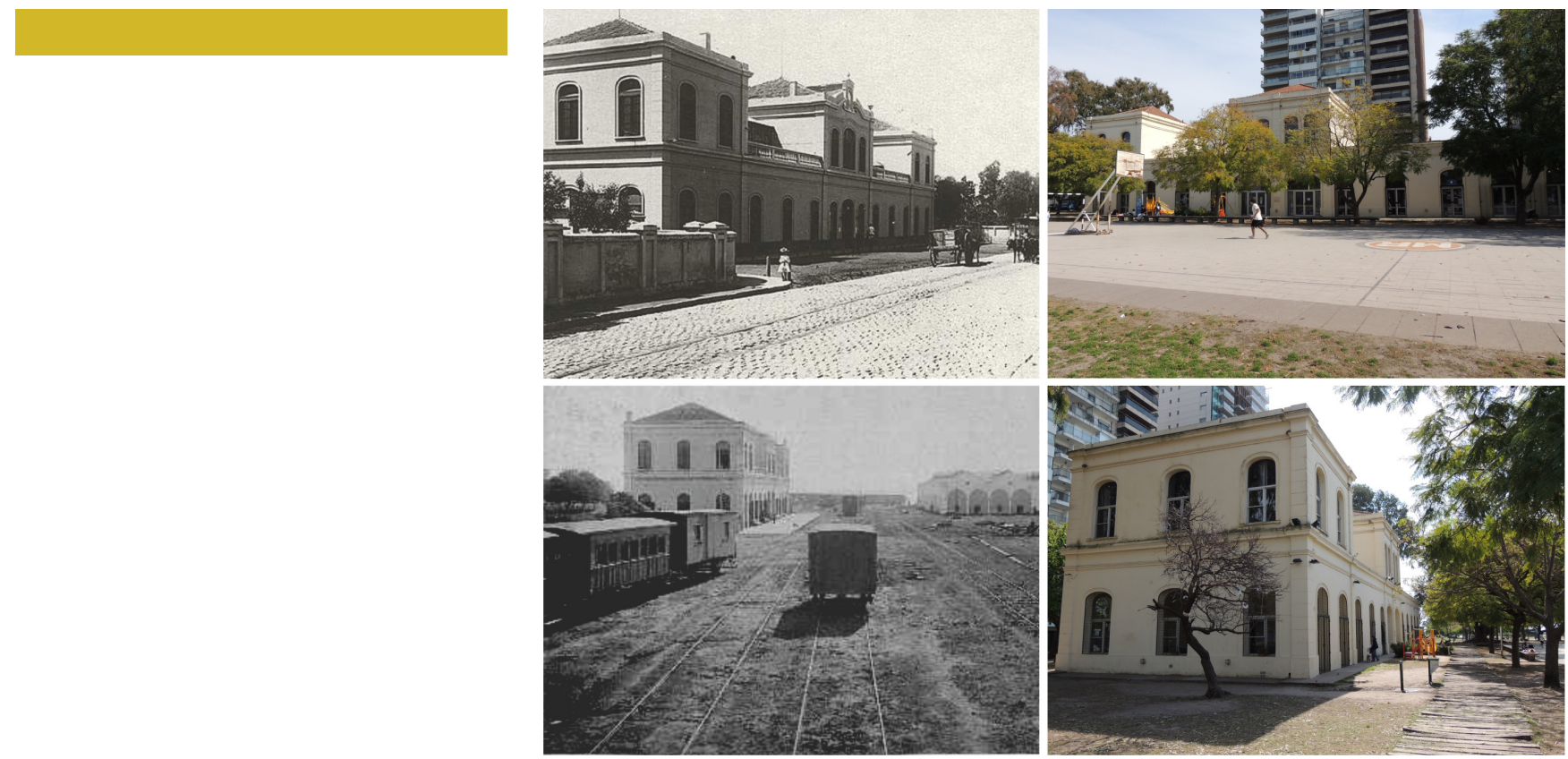

Imagen 2. Estación Oeste Santafesino antes y después (fuente: Archivo Secretaría de Planeamiento de la Municipalidad de Rosario y fotografías de la autora).

\section{$1{ }^{\circ}$ CASO: CREACIÓN DEL PARQUe URQUIZA EN EL EX PREDIO DEL FERROCARRIL OESTE SANTAFESINO.}

Este caso constituye la primera reconversión de un predio perteneciente al sistema ferroviario en un nuevo espacio público para la ciudad, localizado, además, en una posición estratégica junto a la ribera del área central de Rosario. El Ferrocarril Oeste Santafesino, es construido en 1883 -desde Rosario hasta Villa Casilda-, teniendo su principal estación, talleres, galpones, patios de maniobras y muelles en un solar ubicado junto a la barranca del río Paraná. Luego de la nacionalización de los ferrocarriles, en 1948, y en el marco de la reestructuración ferroviaria, el Plan Regulador de 1952 plantea su transformación en un parque para la ciudad. Sin embargo, en un contexto de inestabilidad política en Argentina -con diversos golpes de Estado, como ocurre con la llamada Revolución Libertadora de 1955- estas acciones se postergan hasta los primeros años de la década de 1960. Es a través de la Ley n 16.052 de 1961 que se cuenta con el aval de la Nación para comenzar las tareas de expropiación. De esa manera, el predio mencionado es transformado para la creación de un parque urbano, originalmente llamado de la Ancianidad y luego cambiado a Parque Urquiza.

Si bien se recuperan estas tierras para uso colectivo, el conjunto de instalaciones y construcciones ferroviarias no tienen la misma suerte. Dado que la mayor parte de las vías son desmanteladas, los galpones y talleres son demolidos, quedando en pie, únicamente, la Estación del entonces Ferrocarril Oeste Santafesino. No obstante, la misma aún conserva su fisonomía original, dado que prácticamente no ha sido intervenida en su exterior -salvo tareas de pintura y recuperación de aberturas-, en cambio sí se han realizado modificaciones internas a fin de alojar nuevos usos. La tarea de reacondicionar y rehabilitar la estación se realiza durante la primera década del 2000 y es finalmente reinaugurada en el año 2007, albergando nuevas actividades culturales y educativas para la comunidad. Este edificio, de paredes revocadas con arcos de medio punto, representa un patrimonio de relevancia para la ciudad, ya que se diferencia del resto de las construcciones ferroviarias de ladrillo visto, provenientes de capitales ingleses. También así, desde fines de la década de 1990 se realizan tareas de reacondicionamiento del parque, incorporando mobiliarios, luminarias y forestación. Se destaca que, además del uso para esparcimiento, deportes y recreación de los ciudadanos, en este parque -en especial en el playón deportivo construido junto a la estación- diversas escuelas públicas de la ciudad realizan actividades, registrándose una notable reapropiación colectiva (imagen 2 ). La rehabilitación de este predio hacia una nueva pieza de espacio público urbano, también transforma ampliamente el área circundante. Desde la década de 1970 hasta la actualidad, se produce un fuerte proceso de sustitución edilicia en los lotes frentistas al parque. Las construcciones bajas, generalmente de planta baja y un piso, son reemplazadas por edificios en altura entre medianeras, que superan las diez plantas, tendiendo a conformar una nueva fachada urbana. Se denota una fuerte presión del mercado inmobiliario en este sector, elevándose cuantiosamente el valor del suelo que, al crecer en altura, posibilita contemplar el río Paraná. 


\section{$2^{\circ}$ CASO: PARQUE ESPAÑA NORTE Y EL COMPLEJO DE LA ESTACIÓN ROSARIO CENTRAL. Junto al retorno}

\section{democrático definitivo en Argentina, en}

1983, en la ciudad de Rosario se inicia un nuevo proceso de planeamiento a través del cual se propone rehabilitar el frente costero central, históricamente ocupado por instalaciones ferro-portuarias, y transformarlo en un sistema de espacios públicos ribereños. Bajo esta iniciativa, también se plantea la recuperación de diversas construcciones pertenecientes al puerto $\mathrm{y} / \mathrm{o}$ al ferrocarril, a fin de albergar nuevos usos, generalmente vinculados a la recreación, la administración municipal, la cultura y la gastronomía. Particularmente, en este apartado nos enfocamos en el fragmento correspondiente al Complejo de la Estación Rosario Central, en el parque denominado España Norte, ubicado en el ex predio del Ferrocarril Central Argentino. Se destaca que en este sector se localiza la construcción ferroviaria más antigua de la región, la cual funcionó como la primera estación de pasajeros, combinada con servicios de transporte de cargas. Justamente, es en esta instalación donde el entonces presidente de la Argentina, Bartolomé Mitre, inauguró los trabajos de construcción del Ferrocarril Central Argentino el 19 de abril de 1863. En 1868, a inmediaciones de ésta, se comienzan las obras de la Estación Rosario Central, de manera que dicha instalación original pasó a ser reacondicionada como depósito de cargas, conocido hasta hoy como Galpón No 10 (imagen 3)

A mediados de 1980, en el marco de dicha reconversión costera, desde distintas entidades se reclama la importancia de la preservación de estos componentes de relevancia histórica e identitaria para Rosario y su región². La Municipalidad de Rosario, en el marco del Plan Maestro de la Costa, inicia las tareas de rehabilitación de este predio, junto a otras acciones de transformación urbana como la duplicación de la traza de la avenida ribereña, que conduce a la demolición de diversas instalaciones ferro-portuarias. En este sentido, si bien se rehabilitan construcciones ferroviarias, como el Galpón № 10, la Estación Rosario Central y las edificaciones correspondientes a los tanques de agua de ferrocarriles, también se producen numerosas demoliciones y

- levantamientos de vías férreas. Asimismo,

us estas construcciones son modificadas $\alpha$ parcialmente, en especial en su interior
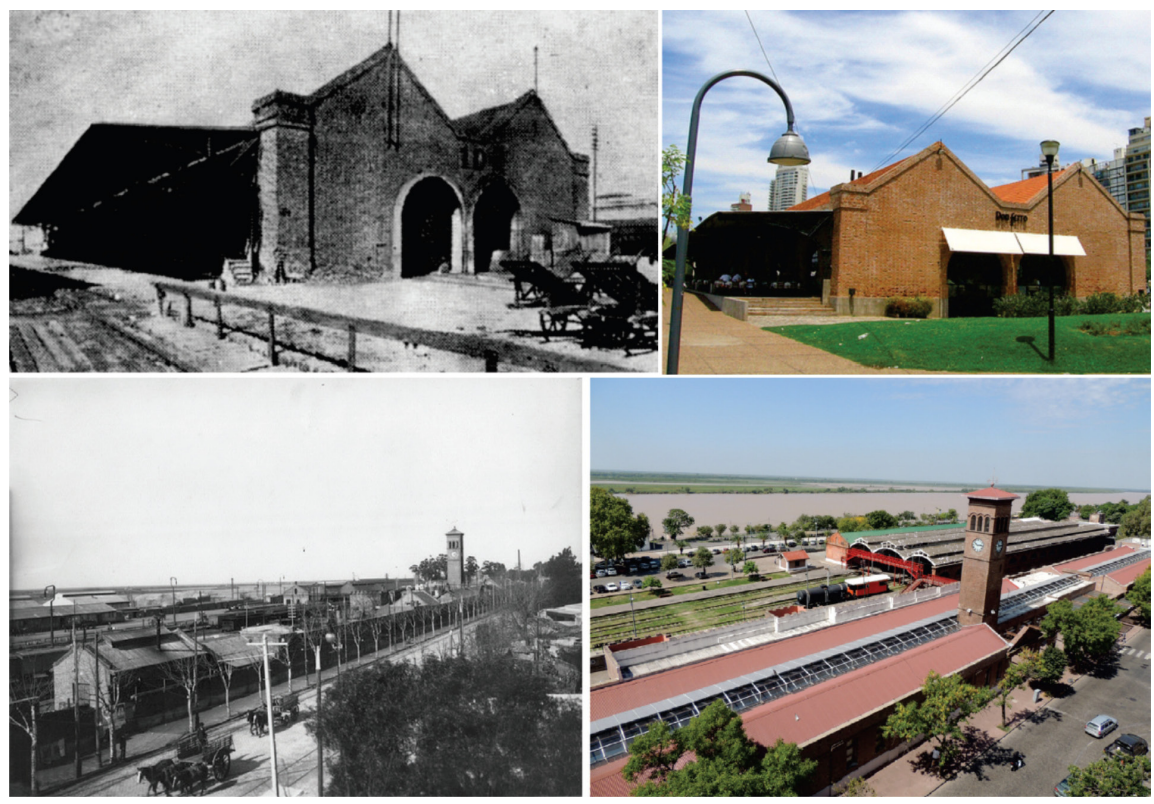

Imagen 3. Antes y después del Galpón Nº 10 y de la Estación Rosario Central (fuente: Colección Miekielevich; Ferrer 2001: fotografías de la autora).
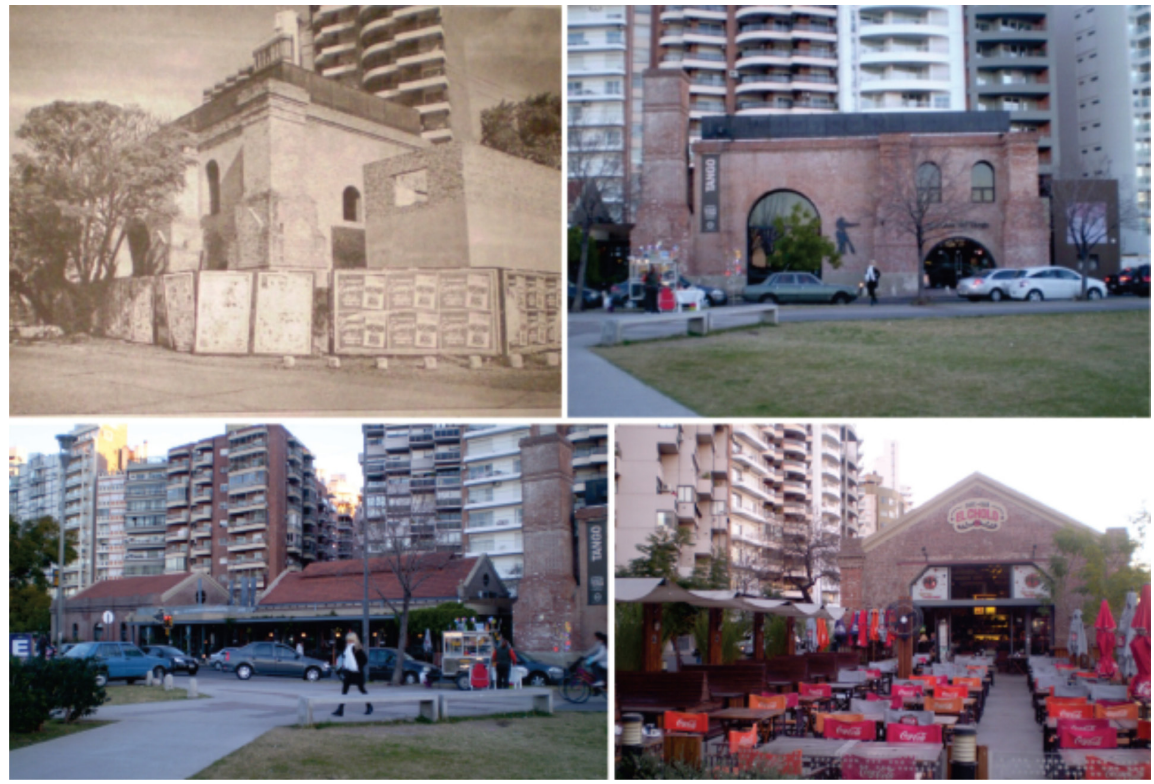

Imagen 4. Actual complejo cultural Casa del Tango (fuente: Archivo Diario La Capital y fotografías de la autora).

a fin de poder albergar nuevas funciones. La inauguración de sus refuncionalizaciones se sucede entre fines de la década de 1990 y la primera década del 2000. Es importante destacar que este parque, al igual que e resto de los espacios públicos ribereños es objeto de una importante apropiación colectiva por parte de la ciudadanía y posibilita una nueva relación entre el tejido urbano y el río Paranás.
A su vez, como en el caso anterior, el sector urbano frentista al parque también atraviesa un fuerte proceso de revalorización inmobiliaria (imagen 4), incrementando ampliamente el valor del suelo, siendo sustituidas muchas construcciones unifamiliares bajas por nuevos edificios en altura y continuando la construcción de la nueva fachada urbana iniciada frente al Parque Urquiza. 
$3^{\circ}$ CASO: PARQUE SCALABRINI ORTIZ EN EL PREDIO DE LOS EX TALLERES

\section{FERROVIARIOS. A fines de la década de}

1890 se instalan los talleres del Ferrocarril Central Argentino en un predio localizado en las inmediaciones del denominado Puerto Norte de Rosario. En dicho sector, se localizaron numerosos galpones y talleres de reparación de coches y vagones, patio de maniobras e incluso dos conjuntos de viviendas destinados al personal ferroviario (Batten Cottage y Morrison Building). Estas instalaciones se encuentran activas hasta mediados de la década de 1990. En 1996, la Municipalidad de Rosario encara la refuncionalización de esta área a través de la Ordenanza N 6.271, que propone el desarrollo del 'Centro de Renovación Urbana Scalabrini Ortiz'. La primera fase de este proyecto consiste en la transformación del sector de los Talleres Ferroviarios -dada su relocalización en la ciudad de Pérez-, a fin de habilitar un nuevo parque público y reconvertir algunas de las construcciones existentes para albergar un nuevo centro comercial y de servicios. Del mismo modo, se refuncionaliza parte de los talleres en un nuevo complejo educativo, en el que se localiza la sede de la Regional VI del Ministerio de Educación y las Escuelas Técnicas $N^{\circ} 474$ y N 467 (imagen 5). Las acciones sobre el patrimonio ferroviario existente son variadas. Por un lado, se demuelen varios galpones y depósitos y se levantan las vías férreas, en especial, en el sector destinado al parque Scalabrini Ortíz, como también en las áreas destinadas a nuevos trazados. Por otro lado, principalmente en el solar propuesto como emplazamiento para el nuevo centro comercial, si bien se restauran diversos galpones correspondientes a los ex talleres, se realizan nuevas intervenciones sobre los mismos, cambiando ampliamente su tipología, dado que se modifican sus interiores para albergar locales comerciales y se realizan nuevas construcciones e infraestructuras que unifican distintas construcciones, con materiales, morfologías y tipologías edilicias diferentes a las originales.

Sin embargo, aún quedan varios componentes sin intervenir, aguardando a ser rehabilitados, y también se encuentran en curso diversos proyectos de rehabilitación patrimonial. Por ejemplo, el plan de revalorización del barrio inglés, a través del cual se plantea restaurar los
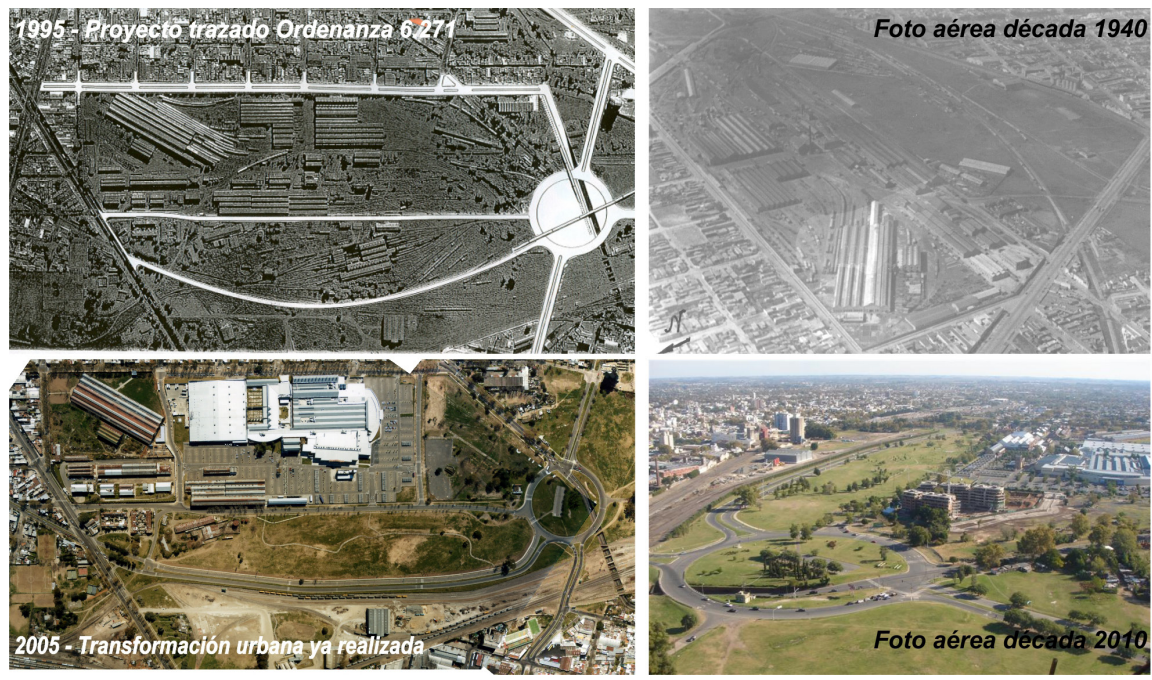

Imagen 5. Antes y después del 'Centro de Renovación Urbana Scalabrini Ortiz' (fuente: Elaboración propia en base a archivo Secretaría de Planeamiento de la Municipalidad de Rosario).
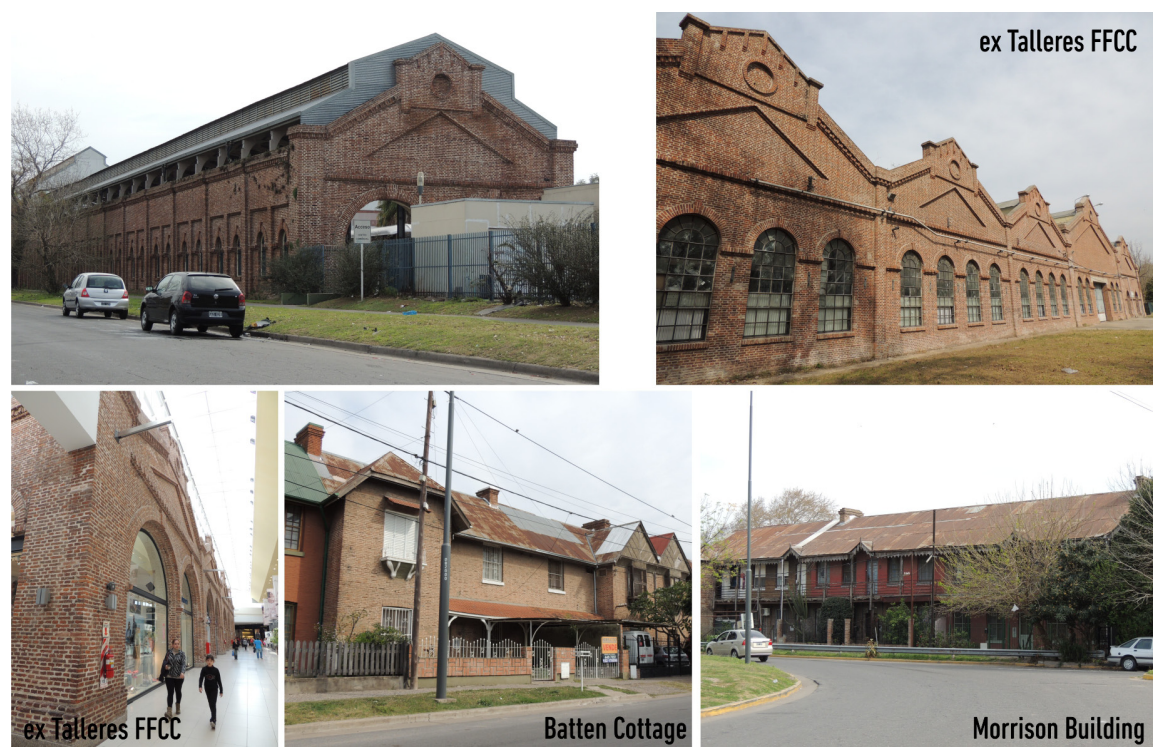

Imagen 6. Reconversión de componentes ferroviarios en torno al nuevo Parque Scalabrini Ortiz (fuente: La autora).

edificios del Batten Cottage, Morrison

Building e Iglesia Anglicana, junto al espacio público circundante (imagen 6)

Se destaca que, con la reconversión de este predio, se crean más de 20 ha de espacio público (Parque Scalabrini Ortíz y trazados) Esta operación produce la regeneración urbana de un importante sector de la ciudad, seguida del desarrollo de la segunda fase, conocida como Puerto Norte. Estas acciones, si bien posibilitan generar costuras dentro de Rosario y transformar una notable cantidad de tierras en nuevos espacios públicos, conducen, a su vez, a un incremento de la plusvalía del suelo, lo que conlleva procesos de gentrificación. De manera que los habitantes tradicionales, vinculados con la identidad productiva de este sector, están presionados a vender sus lotes, debido al alto valor de la tierra que adquieren estos espacios cuyas nuevas construcciones apuntan a clases sociales alta o media-alta. 

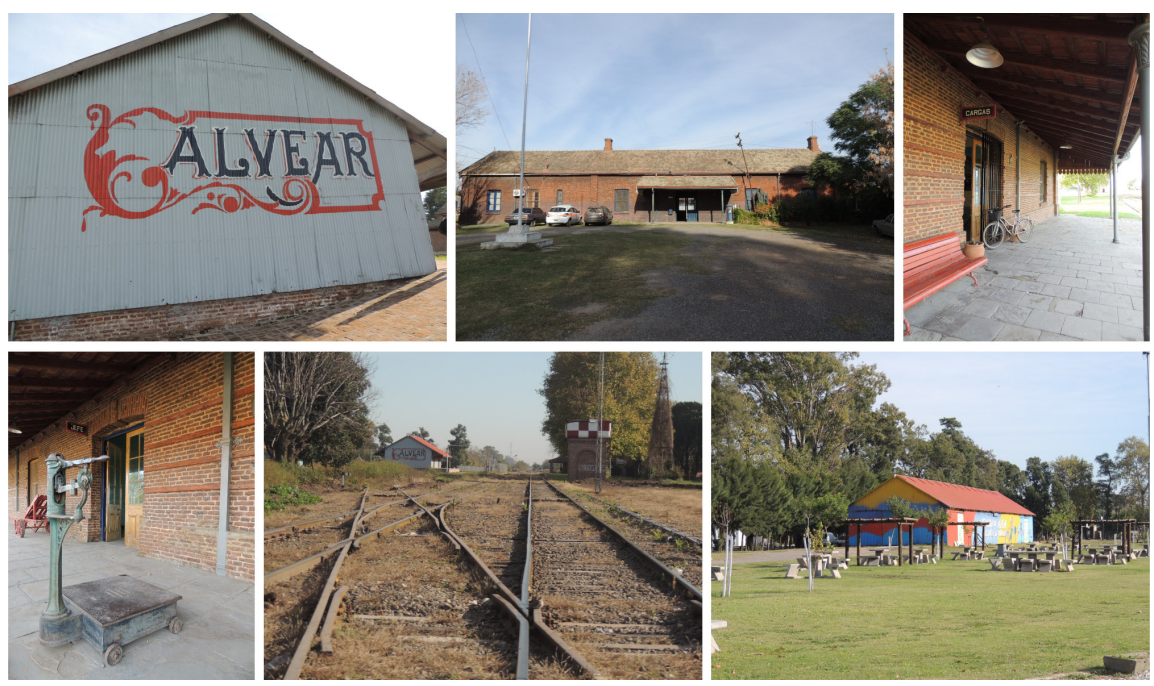

Imagen 7. Refuncionalización del cuadro de estación de Alvear (fuente: La autora). $4^{\circ}$ CASO: ESTACIÓN ALVEAR, LA REAPROPIACIÓN SOCIAL DE LOS CUADROS DE ESTACIÓN EN LOS PUEBLOS Y CIUDADES DEL GRAN

ROSARIO. La rehabilitación del patrimonio

ferroviario que se realiza en la ciudad de

Rosario, en conjunto al desarrollo de espacio público urbano, resulta un antecedente de relevancia para las diversas localidades que comprenden el Gran Rosario. Como mencionamos anteriormente, la mayoría de los poblados del área surgen y se desarrollan en torno a las estaciones ferroviarias, de manera que éstas generalmente se localizan estratégicamente en el centro de las distintas comunas y municipios de la región. Por esto es que muchas localidades inician tareas de refuncionalización de su patrimonio ferroviario, junto a la rehabilitación de los predios correspondientes a los cuadros de estación, a fin de ser reapropiados por toda la comunidad.

Resulta representativo el caso de la comuna de Alvear. Esta localidad se conforma en torno a la estación homónima, creada en 1886 en tierras de las que fuera propietario el Dr. Diego de Alvear. El poblado crece y se desarrolla en torno a la misma. El predio ferroviario queda ubicado en el corazón de la planta urbana y posee una superficie de más de 10 ha. Por ser un solar abierto de grandes dimensiones, situado estratégicamente en la comuna, periódicamente es utilizado por la sociedad para eventos y recreación. Es así que, frente a un uso frecuente de la población -a pesar de presentar sus infraestructuras ferroviarias abandonadas-, esta localidad de 4.451 habitantes ${ }^{4}$ inicia, a principios de siglo XXI, un proceso de restauración de este predio. Por un lado, se realizan tareas de mantenimiento y rehabilitación de las construcciones ferroviarias, en especial de la estación, galpón de depósito, casilla de control y tanque de agua, respetando su fisonomía y estructura original. Es decir, se realizan mayormente tareas de pintura, reacondicionamiento de aberturas, arreglos de cubiertas y recuperación de elementos ferroviarios y de señalética. La estación es refuncionalizada con nuevos usos administrativos de la comuna.

Por otra parte, se reacondiciona el espacio abierto a través de la incorporación de luminarias, bancos y un camino de ripio en el ingreso al solar, como también se adicionan mesas y bancos de hormigón, pérgolas de madera, forestación y luminarias en el sector junto al galpón que ha sido rehabilitado para albergar actividades culturales (imagen 7). Es importante remarcar que el ferrocarril de cargas Nuevo Central Argentino sigue activo y atraviesa diariamente este conjunto. Sin embargo, el uso del transporte ferroviario convive con las actividades de recreación culturales y deportivas que realiza la comunidad, debido a la sectorización de los distintos usos. La población de Alvear se ha reapropiado de este componente urbano, resignificando la identidad ferroviaria de la localidad, y siendo este predio un lugar de encuentro y sociabilización colectiva. Es importante remarcar que estos cuatro casos son solo algunas de las acciones de refuncionalización del patrimonio ferroviario regional y desarrollo de espacio público. Si bien hay muchas instalaciones que han sido desmanteladas y demolidas, aún quedan varias en desuso y a la espera de una transformación, como también hay otras que todavía se encuentran activas. 


\section{CONCLUSIONES.}

El análisis de los casos estudiados nos permite comprender que las intervenciones de refuncionalización del patrimonio ferroviario en Rosario y su región, se encuentran mayormente articuladas con la generación de espacio público y al desarrollo de actividades recreativas, culturales, deportivas, entre otras, que posibilitan reapropiaciones colectivas y de socialización de la comunidad local. No obstante, a pesar de la regeneración urbana que significan estas intervenciones, las mismas no siempre se han sustentado en un profundo análisis previo de intervención patrimonial, dado que se han demolido muchos componentes ferroviarios de gran relevancia o se han realizado importantes modificaciones que alteran ampliamente la tipología original. Por ejemplo, el levantamiento de la mayoría de vías férreas sobre la ribera central, imposibilita en la actualidad activar un transporte ferroviario de pasajeros que articule el sistema de espacios públicos generado recientemente. Por otra parte, estos proyectos traen aparejado el aumento de plusvalías e incremento del valor del suelo en áreas aledañas a los mismos, conduciendo a una notable transformación de las construcciones cercanas - por nuevas tipologías de torres o edificios en altura-, como también generan procesos de gentrificación.
De esa manera, resulta necesario establecer nuevos mecanismos e instrumentos de planeamiento que establezcan estudios detallados por parte de técnicos y agentes especializados diversos, para que las acciones a realizar no destruyan el valor de estos recursos. Asimismo, es fundamental contribuir a un mayor compromiso y una mayor participación activa de la sociedad en los proyectos de intervención que involucren la transformación de componentes identitarios locales y regionales, a fin de establecer una mayor integración entre el pasado, el presente y el futuro. $\mathbf{\Delta} \boldsymbol{0}$

\section{REFERENCIAS}

Beltrản-Beltrản, L., 2011، "Las antiguas redes ferroviarias y su recuperación para impulsar el desarrollo regional. Editorial." Apuntes, 24, (1), 6-7.

Borja, J. y Muxi, Z., 2003. El espacio público, ciudad y ciudadanía. Barcelona: Electa.

Ferrer, A. 2001. Ferrocarriles en Rosario. Rosario: Asociación Rosarina Amigos del Riel.

Galimberti, C., 2015. La reinvención del rio. Procesos de transformación en la ribera de la Región Metropolitana

de Rosario. Rosario: UNR Editora.
Sabaté, J. 2010 “De la preservación del patrimonio a la ordenación del paisaie: intervenciones en paisajes culturales (Europa-Latinoamérica)." Labor \& Engenho, 4, (1), 10-25 Sabaté, J., 2004. "Paisajes culturales. El patrimonio como recurso básico para un nuevo modelo de desarrollo." Urban, 9, 8-29 